Research Article

\title{
The Influence of Confining Stresses on Rock Fragmentation, Thrust Force, and Penetration Energy in Sandstone Indentation Tests Using Disc Cutters
}

\author{
Gaofeng Wang $\mathbb{D}^{1,2}$ Ting Ren $\mathbb{D}^{1},{ }^{3}$ and Gaolei Zhu $\mathbb{D}^{1,2}$ \\ ${ }^{1}$ School of Mines, China University of Mining and Technology, Xuzhou, Jiangsu 221116, China \\ ${ }^{2}$ State Key Laboratory of Coal Resources and Safe Mining, China University of Mining and Technology, \\ Xuzhou, Jiangsu 221116, China \\ ${ }^{3}$ Faculty of Engineering and Information Sciences, University of Wollongong, Wollongong, NSW 2522, Australia
}

Correspondence should be addressed to Ting Ren; ting_ren@uow.edu.au

Received 27 January 2021; Revised 9 February 2021; Accepted 11 March 2021; Published 2 April 2021

Academic Editor: Chiara Bedon

Copyright $\odot 2021$ Gaofeng Wang et al. This is an open access article distributed under the Creative Commons Attribution License, which permits unrestricted use, distribution, and reproduction in any medium, provided the original work is properly cited.

\begin{abstract}
Hard rock Tunnel Boring Machines (TBMs) engaging disc cutters as cutting tools have been employed in considerable underground coal mines to accommodate the requirement of more stone drivage as operations are going deeper. This study conducted a set of disc cutter indentation tests to explore the influence of confining stresses on rock fragmentation, thrust force, and penetration energy on sandstone, which is commonly encountered in underground coal mines. The test results show that there exists a critical confining stress, under which the maximum thrust force and penetration energy keep increasing with confining stress mounting while the maximum thrust force and penetration energy will decrease or flatten if it is surpassed. By combining with previous studies and comparing the critical confining stress values to the rock mechanical properties' values, the critical value is most likely to be of cohesion. For subsurface rock fragmentation, the Constant Cross Section (CCS) disc cutter indentation has denser cracks and their orientations are more lateral than those under the V shape one; the V shape disc cutter indentation is less sensitive to confining stresses, with no notable increase of crack number and crack reorientation with increasing confinement. Thus, the CCS disc cutter is more favorable than the V shape one from the perspective of rock fragmentation under confining stresses.
\end{abstract}

\section{Introduction}

Stone drivage has been in increasing demand for underground coal mines. Depletion of shallow resources forces them to go deeper. The deepest underground coal mining operation in China has been over 1500 meters beneath the ground surface, and numerous others are deeper than 1000 meters $[1,2]$. With such large overburden depths, coal seams sit in high-stress regimes and hold more methane [3-7]. For that, stone roadways are needed to facilitate safe mining operations. Firstly, high ground stress deteriorates the stability of underground workings, which makes coal mains not feasible; to obtain reasonable stability, the mains need to be constructed in a more competent stone floor. Secondly, high gas content, combined with high ground stress, makes coal seams prone to outbursts. Coal gates in outburst prone seams need to be destressed and degassed during development to eliminate risks. In many mines, destressing and degassing operations are carried out from stone roadways beneath longwall panels. Last but not least, numerous gassy mines also construct stone roadways above longwall panels to accommodate goaf gas drainage to avoid methane buildups at longwall faces. In conclusion, stone drivage is in a great and growing demand for deep underground coal mines [8-11]. Hard rock Tunnel Boring Machines (TBMs) engaging disc cutters as rock breaking tools have been used in considerable deep underground coal mines to accommodate the requirement of stone drivage [12-14].

In the rock cutting process, thrust force applied from TBM cutting heads makes disc cutters penetrate into the 
rock, as illustrated in Figure 1, and incurs rock fragmentation and penetration energy. Magnitudes of thrust force and penetration energy are indicators of cutting easiness. Rock fragmentation under a disc cutter mainly includes forming a crushed zone and incurring cracks. Crack development patterns reflect the modes of failures; radial cracks are often caused by tensile failure, while lateral cracks, that is, side chipping, indicate shear failure $[15,16]$. Study of rock fragmentation, thrust force, and penetration energy under confining stresses improves understanding of TBM rock breaking in deep underground mines, which presents a prerequisite for refining cutting force prediction models and practicable feasibility study for underground coal mine TBM projects.

Disc cutter cutting force prediction is a basis for TBM cutting head design, optimization, and advance rate prediction. Numerous researchers have attempted to develop accurate cutting force prediction models. For V shape disc cutters which were adopted in the early days of TBMs, Evans, Roxborough and Philips, and Ozdemir et al. proposed their cutting force prediction models, respectively [17-20]. Along with TBMs' application in hard rock tunnelling, CCS disc cutters became more predominant than $\mathrm{V}$ shape ones in those cases [21]. Rostami and Ozdemir introduced new models to cover the CCS disc cutters [22]. Although researchers have been refining the cutting force prediction models, there is still no widely accepted cutting force prediction model taking due consideration of the factor of confining stresses $[23,24]$.

Researchers have proposed various rock-breaking mechanisms under confining stresses by disc cutters, which often conflict with each other. It means the influence of confining stresses on disc cutting is still not clear. Tarkoy and Marconi [25] proposed an unfavorable influence of high confining stresses on rock boreability by referring to field data from Star Mine tunnels driven with 1200-2000 m overburden [25]. Klein et al. [26], in contrast to Tarkoy and Marconi, argued favorable effects of high confining stresses on TBM boring based on the Field Penetration Index (FPI) data from other four TBM tunnelling projects [26]. Innaurato et al. [27] conducted laboratory disc cutter indentation tests on two hard rocks and found that thrust force increased with the confinement mounting [27]. Yin et al. [28] studied the influence of confining stresses on disc cutting rock fragmentation with up to $25 \mathrm{MPa}$ confinement on marble and granite samples. The study found the existence of a critical confining stress value for the marble samples, under which the thrust force for crack initiation keeps increasing, while they decrease when the confining stress is higher than the critical value [28]. The governing factor for the critical value was however not identified in the study, and only one CCS disc cutter was adopted in the tests. Chen and Song [29] studied the confining stresses' influence on penetration energy, which is calculated by integrating the thrust force with indentation displacement. The penetration energy continuously increased with the rising of confining stresses [29]. However, only a CCS disc cutter was utilized in the tests. Conclusively, the influence of confining stresses on disc cutting is notable and not yet fully explored, the

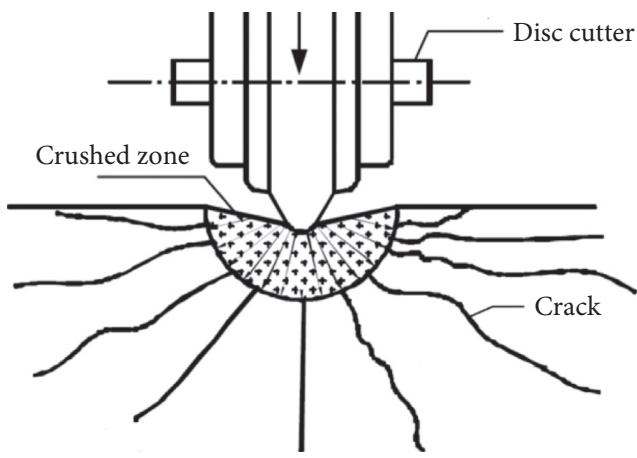

FIGURE 1: Schematic diagram of disc cutter's penetration into the rock.

mechanisms proposed by previous researcher conflict with each other. In addition, the aforementioned finding of critical confining stress needs to be further studied.

Different rocks might undergo different rock cutting mechanisms. Rocks utilized in previous studies are rarely encountered in underground coal mines. So, findings from the aforementioned studies bear questionable relevance for underground coal mine TBM operations. To remedy the shortcomings, a series of laboratory tests with bilateral confinement were conducted on sandstone, which is a commonly encountered stone in underground coal mines. In addition, both CCS and V shape disc cutters were used.

\section{Test Methodology}

Rock fragmentation under a disc cutter is mainly the function of thrust force. So, the cutter-rock interaction can be treated as an indentation process. This study adopts the indentation methodology to conduct the laboratory tests.

\subsection{Test Equipment}

2.1.1. The Cutters. The cutters used in the indentation tests are shaped as a portion of the $450 \mathrm{~mm}$ diameter and $30 \mathrm{~mm}$ width TBM cutter rings, as shown in Figures 2 and 3. For the $\mathrm{V}$ shape cutter, its included edge angle is $80^{\circ}$.

2.1.2. The Confining Box. To apply the bilateral confinement on sandstone blocks, a confining box was designed to accommodate the sandstone blocks. The sandstone block is positioned at a corner of the box, and then two steel plates are placed against the two open sides of the sandstone block. Two hydraulic flat jacks are placed between the box and steel plates to apply the confining pressure, as shown in Figure 4.

2.1.3. Penetration Platform. The indentation tests are set upon an AVERY computer-controlled electrohydraulic servo machine with a load capacity of $5000 \mathrm{kN}$, as shown in Figure 5. The confining box is placed on the bottom platen while the disc cutter is placed at the upper platen. The two flat jacks are inflated with two hydraulic hand pumps to apply confining stresses. 


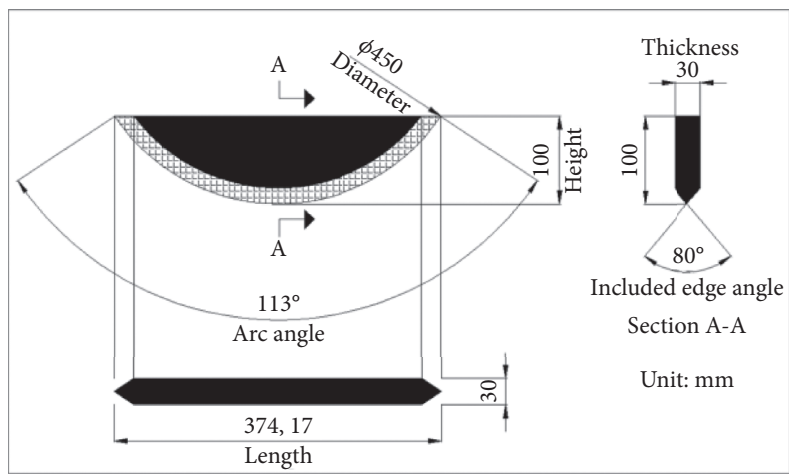

(a)

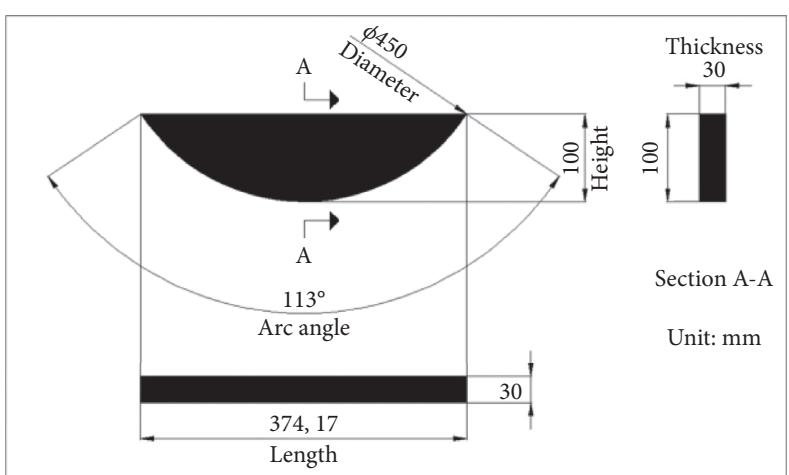

(b)

FIGURE 2: Fabricating drawings of the designed cutters: the V shape one (a) and CCS one (b).

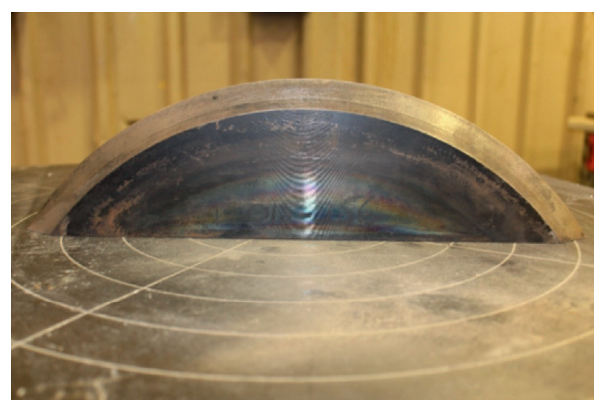

(a)

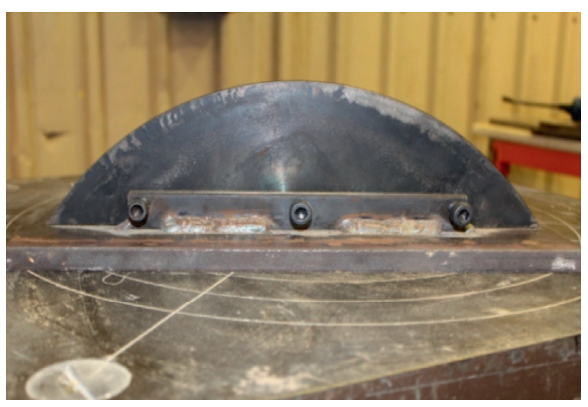

(b)

Figure 3: Fabricated cutters: the V shape one (a) and CCS one (b).

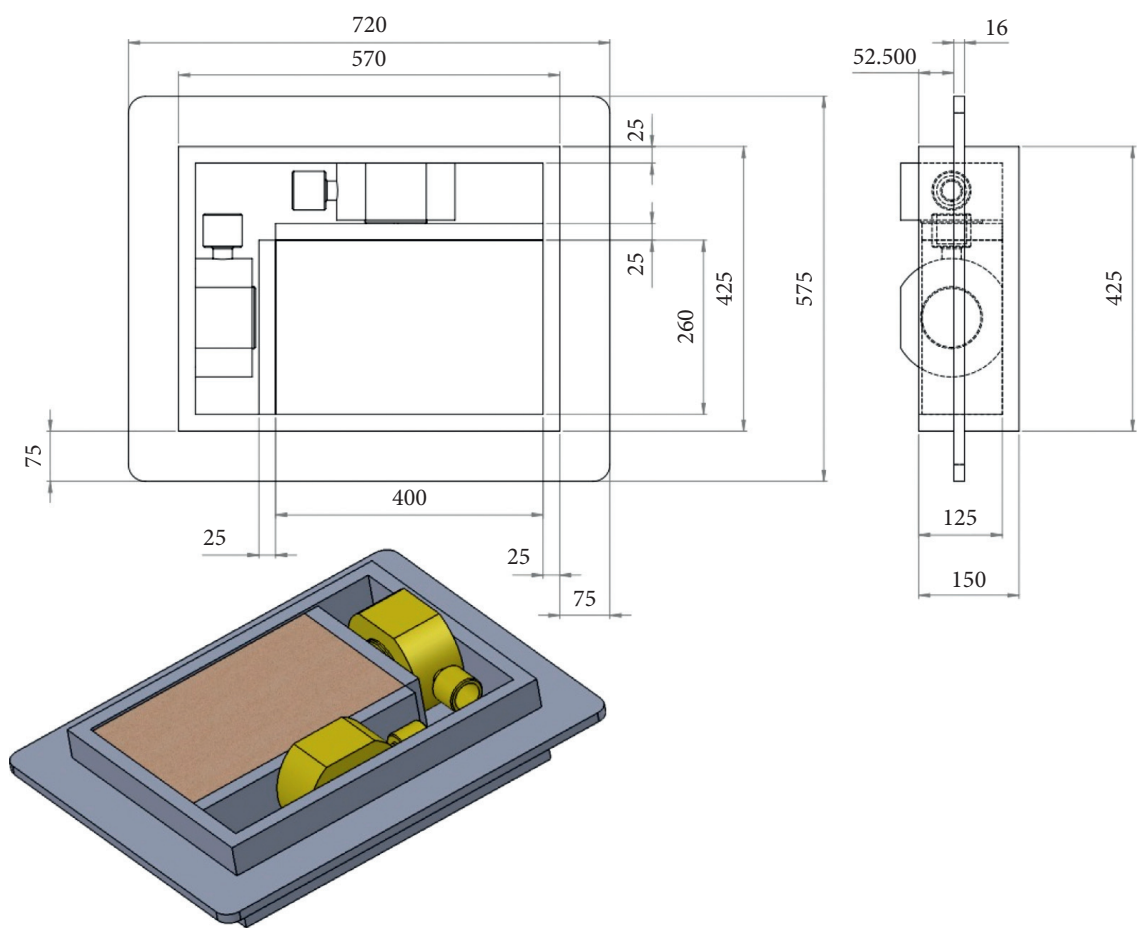

Figure 4: Steel box designed for applying confining stresses (all dimensions in $\mathrm{mm}$ ). 


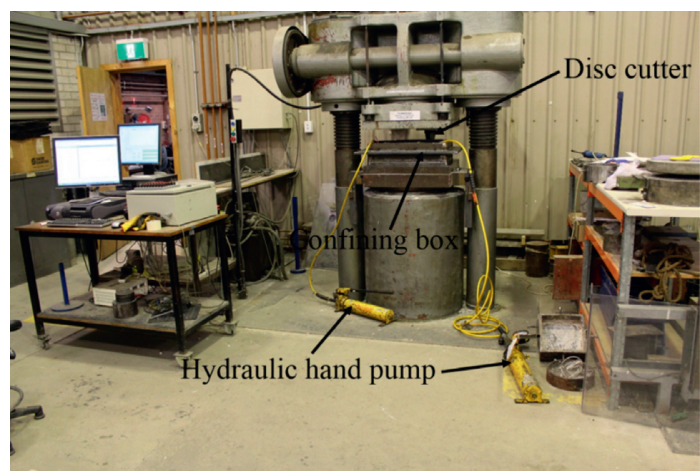

Figure 5: The indentation test platform.

2.2. Rock Sample Preparation. The background of this laboratory study is the application of TBMs in underground coal mines. Sandstone is the most common surrounding rock in underground coal mines. As different rock types have distinctive failure patterns under disc cutting due to the complexity of the rock properties in nature; it is hard to generalize a specific research outcome applicable for all rocks. Sandstone is chosen for this study to obtain meaningful guidelines for the application of TBMs in underground coal mines.

To ensure that the tested sandstone blocks have consistent physical and mechanical properties, all rock blocks were cut from a single large lump, from a quarry in Wollongong. They were prepared into a specified dimension of $400 \mathrm{~mm} \times 260 \mathrm{~mm} \times 120 \mathrm{~mm}$.

The main properties of the sandstone are summarized in Table 1.

Uniaxial and triaxial tests were conducted on an Instron loading machine according to ISRM suggested methods [30]. The dimensions of all samples are $54 \mathrm{~mm}$ in diameter and $120 \mathrm{~mm}$ in height.

\subsection{Testing Design and Procedure}

2.3.1. Test Design. Eight rock specimens are tested: four ones under the CCS disc cutter and the other four ones under the $\mathrm{V}$ shape disc cutter. The variable parameters of the study are disc cutter patterns and confining stresses. Two sequential cuts are designed for each specimen on the top surface, as illustrated in Figure 6. The first cut's penetration is $6 \mathrm{~mm}$ and the second cut's penetration is $9 \mathrm{~mm}$. Determination of each cut's position is based on reviewing of research outcome on spacing-penetration ratio. The spacing-penetration ratio is normally lower than 10 [31]. To eliminate the edge effect, the first cut's spacing to the edge is adopted as $85 \mathrm{~mm}$, and the second cut's spacing to edge is adopted as $125 \mathrm{~mm}$, by further adding safety factors. In addition, the spacing between the two cuts is $190 \mathrm{~mm}$, which is much larger than 10 times the deeper penetration of $9 \mathrm{~mm}$. Thus, the two cuts neither have edge effect nor interfere with each other.

The bilateral confining stresses are provided by inflated flat jacks, as shown in Figure 5. The confining stresses are 0, 3,6 , and $9 \mathrm{MPa}$, respectively, with the same values in two directions for the same sandstone specimen. Penetration
Table 1: Properties of the sandstone used in laboratory tests.

\begin{tabular}{lc}
\hline Rock properties & Property values \\
\hline Specific density & $2230 \mathrm{~kg} / \mathrm{m}^{3}$ \\
Uniaxial compressive strength (UCS) & $38.43 \mathrm{MPa}$ \\
Brazilian tensile strength & $5.29 \mathrm{MPa}$ \\
Cohesion & $6.79 \mathrm{MPa}$ \\
Internal friction angle & $47.47^{\circ}$ \\
Young's modulus & $48.60 \mathrm{GPa}$ \\
Poisson's ratio & 0.16 \\
\hline
\end{tabular}

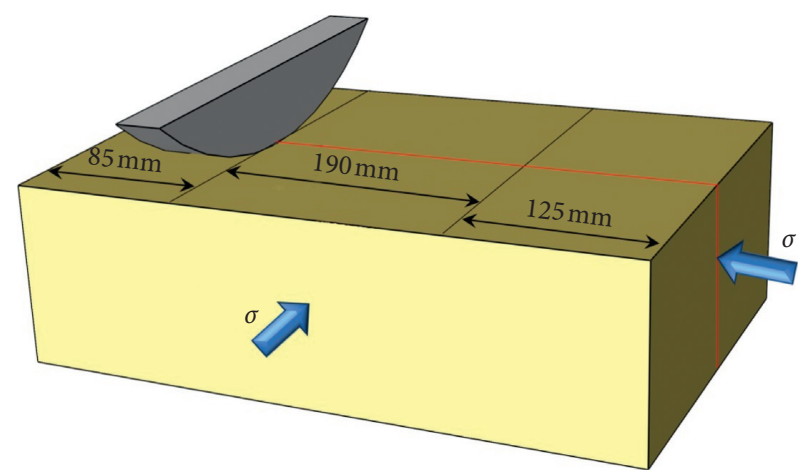

Figure 6: Schematic representation for the positioning of the indentation cuts.

forces of disc cutters are applied by the hydraulic servo compression machine. The vertical penetration process is controlled by displacement with the final penetration depths of 6 and $9 \mathrm{~mm}$ for the first and second cuts, respectively. Tested sandstone blocks are then cut to examine the subsurface crushed zone and crack development after indentation tests.

2.3.2. Test Procedure. There are two cuts for each sample, and the testing procedure is as follows:

(i) The sandstone specimen is put into the confining box, and the steel plates and hydraulic flat jacks are set as illustrated in Figure 4.

(ii) The confining box is then placed onto the testing platform, as shown in Figure 5. Subsequently, the flat jacks are inflated with hydraulic hand pumps to apply designated confinement stresses onto the sandstone samples.

(iii) The designated cutter is installed onto the hydraulic servo machine and then located to the designated positions. Penetration load is applied to the sandstone sample with displacement control, in which the penetration depth and thrust force variations are recorded.

(iv) Once the indentation cuts are finished, the servo machine is unloaded. Sequentially, the flat jacks are deflated, and the confining box is retrieved from the test platform. The sandstone specimen is then collected from the confining box, and the confining 
box will be cleaned to accommodate another specimen for being tested.

(v) The tested specimen is diamond cut into four pieces to study the subsurface rock fragmentation under the disc cutter, as shown in Figure 7.

\section{Results}

3.1. Confining Stresses' Influence on Cutting Forces. The CCS disc cutter thrust cutting force evolution patterns under different confining stresses are illustrated in Figure 8. It shows that the thrust force disparities among different confining stresses are of a marginal extent with penetration lower than $3 \mathrm{~mm}$. After that, thrust forces fluctuate with large amplitude up to the ultimate penetrations of $6 \mathrm{~mm}$ and $9 \mathrm{~mm}$, and the disparities are irregular.

TBM thrust capacity is a multiplication of single cutter thrust force by the number of cutters. Thus, getting the maximum load for a single cutter is the basis for determining the thrust capacity for the TBM propelling system design. From this point of view, the influence of confining stress on maximum thrust force is of great interest. The influence identified in this study is presented in Figure 9.

Figure 9(a) shows the maximum thrust force values for the CCS disc cutter with a penetration of $6 \mathrm{~mm}$. The maximum thrust force values are $249,368,432$, and $348 \mathrm{kN}$ under confining stresses of $0,3,6$, and $9 \mathrm{MPa}$, respectively. Maximum thrust force increases with confining stresses mounting when it is lower than $6 \mathrm{MPa}$, while maximum thrust force begins to decrease from some point between 6 and $9 \mathrm{MPa}$ of confinement. Figure 9 (b) shows the maximum thrust force values for the CCS disc cutter with the ultimate penetration of $9 \mathrm{~mm}$. It shows that the load reaches 233,378 , 480 , and $483 \mathrm{kN}$ under the confinement of $0,3,6$, and $9 \mathrm{MPa}$, respectively. The correlation between confinement and maximum thrust force is similar to that of $6 \mathrm{~mm}$ penetration, while the maximum thrust force begins to flatten instead of decreasing from some point between 6 and $9 \mathrm{MPa}$ of confinement.

The $\mathrm{V}$ shape disc cutter thrust force evolution patterns under different confining stresses are illustrated in Figure 10. Figure 10(a) shows the thrust force curves with penetration up to $6 \mathrm{~mm}$. Thrust force disparities among different confining stresses are of the marginal extent and irregular with penetration up to $3.3 \mathrm{~mm}$. Notable drops appear at 5, 5.4, and $3.3 \mathrm{~mm}$ afterwards for 3,6 , and $9 \mathrm{MPa}$, respectively, which present very irregular disparity patterns. Figure 10(b) shows the thrust force curves with penetration up to $9 \mathrm{~mm}$. The thrust force disparities among different confining stresses are irregular but generally increase with increasing confining stresses, which is different from that of $6 \mathrm{~mm}$ ultimate penetration. The most notable change is the drop at $6.5 \mathrm{~mm}$ penetration for $0 \mathrm{MPa}$ of confinement.

The influence of confining stress on maximum thrust force of V shape disc cutter is presented in Figure 11. For ultimate penetration of $6 \mathrm{~mm}$, Figure 11(a) shows that the maximum thrust force reaches 132, 105, 111, and $97 \mathrm{kN}$ under confining stresses of $0,3,6$, and $9 \mathrm{MPa}$, respectively. No correlation is found between confining stress and

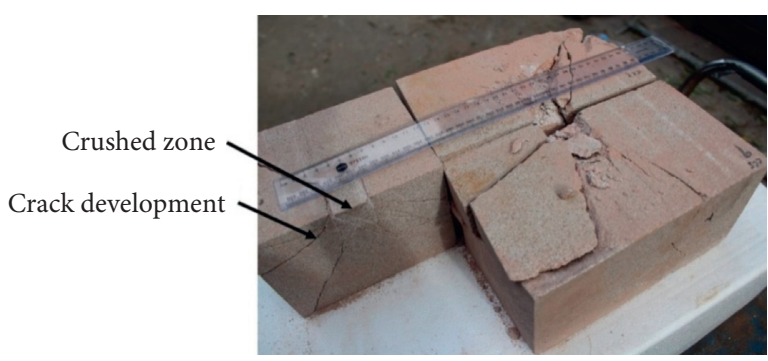

FiguRE 7: Observation of rock fragmentation.

maximum thrust force. For ultimate penetration of $9 \mathrm{~mm}$, Figure 11(b) shows that maximum thrust force reaches 113 , 202,224 , and $242 \mathrm{kN}$ under confining stresses of $0,3,6$, and $9 \mathrm{MPa}$, respectively, which means a positive correlation exists between confining stress and maximum thrust force. In summary, the confining stress's influence on $\mathrm{V}$ shape disc cutter thrust force is totally different for $6 \mathrm{~mm}$ penetration and $9 \mathrm{~mm}$ penetration, which makes it irregular and unpredictable.

3.2. Disc Cutter Pattern's Influence on Thrust Cutting Forces. Thrust cutting force evolution patterns under different disc cutters with $9 \mathrm{~mm}$ penetration are illustrated in Figure 12. It indicates that CCS disc cutter thrust forces are significantly higher than those of $\mathrm{V}$ shape disc cutter. Under $0 \mathrm{MPa}$ confinement, the maximum thrust forces are 113 and $233 \mathrm{kN}$ for the V shape disc cutter and the CCS disc cutter, respectively; the maximum value for the CCS disc cutter is $206.4 \%$ that of the V shape disc cutter. Under $3 \mathrm{MPa}$ confinement, the maximum thrust forces are 202 and $378 \mathrm{kN}$ for the $\mathrm{V}$ shape disc cutter and the CCS disc cutter, respectively; the maximum value for the CCS disc cutter is $187.6 \%$ that of the $\mathrm{V}$ shape disc cutter. Under $6 \mathrm{MPa}$ confinement, the maximum thrust forces are 224 and $480 \mathrm{kN}$ for the $\mathrm{V}$ shape disc cutter and the CCS disc cutter, respectively; the maximum thrust force for the CCS disc cutter is $214.4 \%$ that of the $\mathrm{V}$ shape disc cutter. Under $9 \mathrm{MPa}$ confinement, the maximum thrust forces are 242 and $484 \mathrm{kN}$ for the $\mathrm{V}$ shape disc cutter and the CCS disc cutter, respectively; the maximum thrust force for the CCS disc cutter is $200.0 \%$ that of the V shape disc cutter. Conclusively, thrust forces for the CCS disc cutter are nearly two times those of the V shape disc cutter under the given experimental setup.

3.3. Confining Stress's Influence on Crack Development. After indentation tests, the sandstone blocks were diamond cut to examine the subsurface crack development under different disc cutter patterns and confining stresses, as shown in Figures 13 and 14.

Figure 13 shows that confining stresses influence the crack number and orientation under the CCS disc cutter. Radial and lateral crack numbers increase with confinement rising. In addition, radial crack orientation turns more laterally with confining stresses increasing.

Figure 14 shows the crack development with different confining stresses under the V shape disc cutter. All cracks 


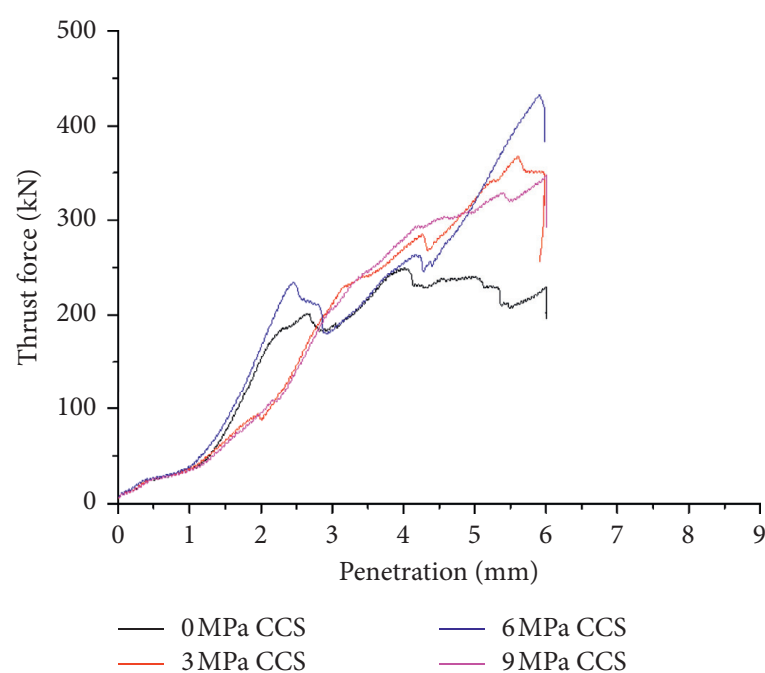

(a)

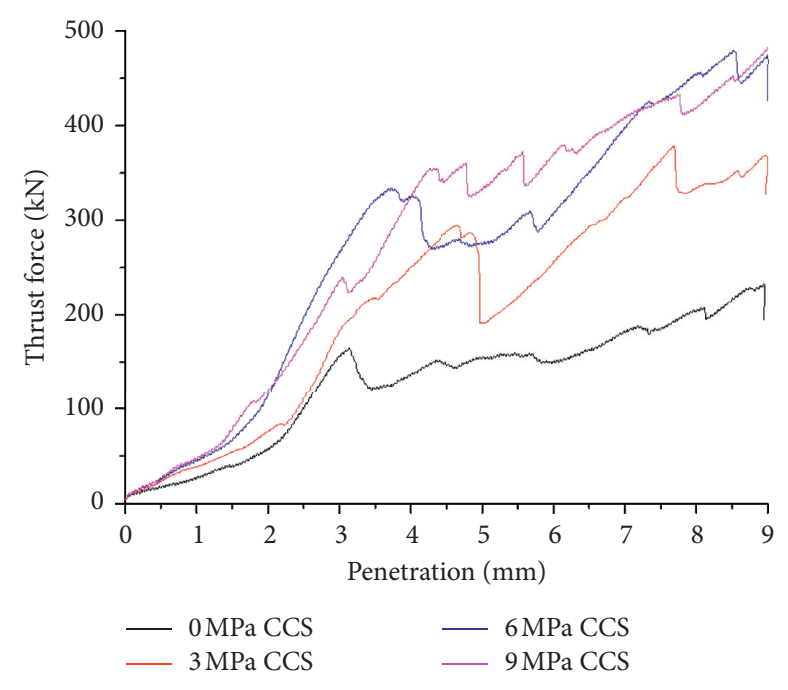

(b)

FIgURE 8: Thrust cutting force evolution patterns under the CCS disc cutter. (a) Ultimate penetration $=6 \mathrm{~mm}$; (b) ultimate penetration $=9 \mathrm{~mm}$.

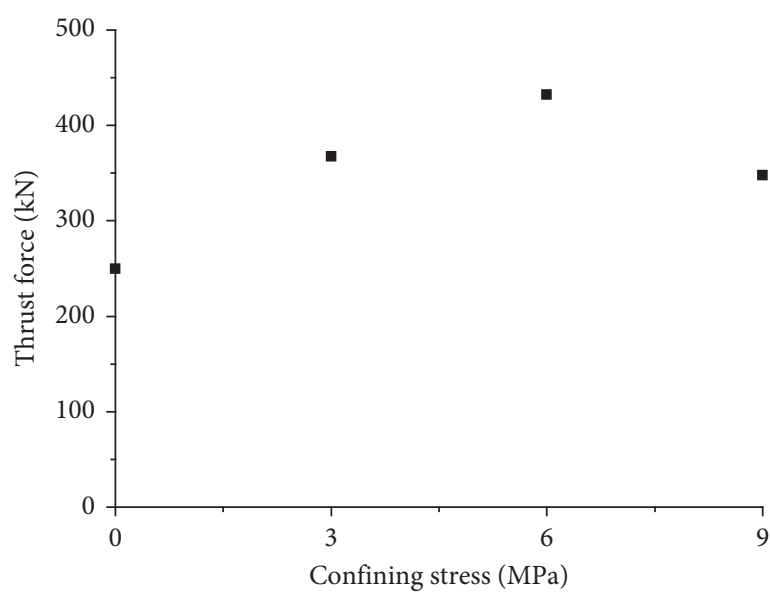

Maximum thrust force for CCS $6 \mathrm{~mm}$ penetration

(a)

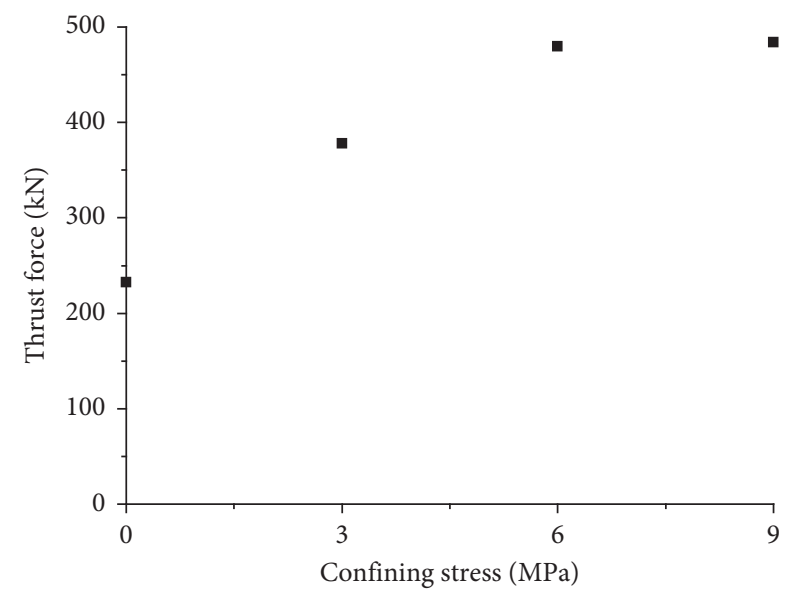

Maximum thrust force CCS $9 \mathrm{~mm}$ penetration

(b)

Figure 9: Confining stresses' influence on maximum thrust force for the CCS disc cutter. (a) Ultimate penetration $=6 \mathrm{~mm}$; (b) ultimate penetration $=9 \mathrm{~mm}$.

initiate from the cutter tip contact. Confining stress variation does not have a notable influence on crack development from the perspectives of crack number and orientation.

In summary, indentation under different disc cutters induces distinctive crack patterns with the same penetration and confining stresses. The CCS disc cutter indentation has denser cracks and their orientations are more lateral, which is favorable for rock cutting. The $\mathrm{V}$ shape disc cutter indentation is less sensitive to confining stresses, with no notable increase in crack number and crack reorientation. So, the CCS disc cutter is better for rock fragmentation.
3.4. Confining Stress's Influence on Penetration Energy. Penetration energy, which is calculated by integrating the thrust force with displacement, is an important indicator of cutting efficiency, that is, boreability. The relationship between the penetration energy and confining stress is illustrated in Figures 15 and 16.

Figure 15(a) shows the penetration energy values for $6 \mathrm{~mm}$ penetration for the CCS disc cutter. They are 967, 1112,1193 , and $1104 \mathrm{Nm}$ under confining stresses of $0,3,6$, and $9 \mathrm{MPa}$, respectively. Figure $15(\mathrm{~b})$ shows the values for $9 \mathrm{~mm}$ penetration, which are $1154,1883,2417$, and $2501 \mathrm{Nm}$ under confining stresses of $0,3,6$, and $9 \mathrm{MPa}$, respectively. It 


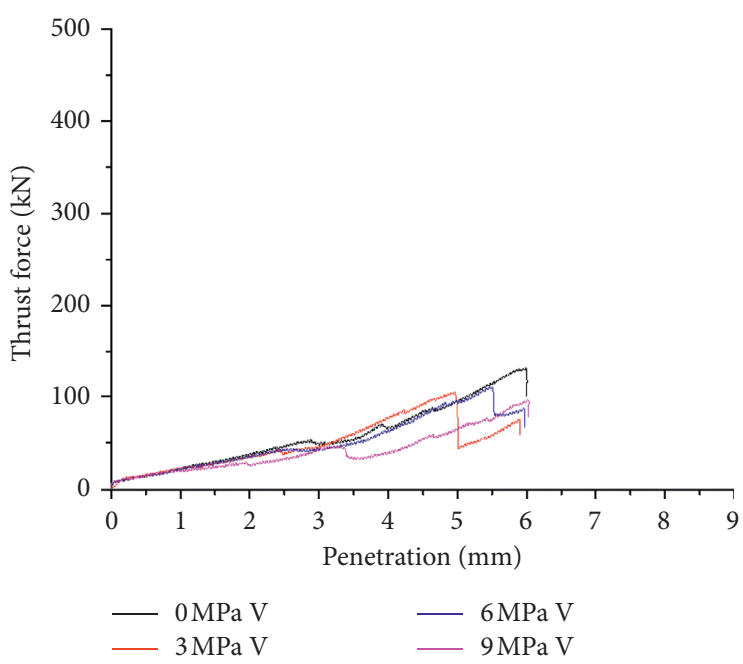

(a)

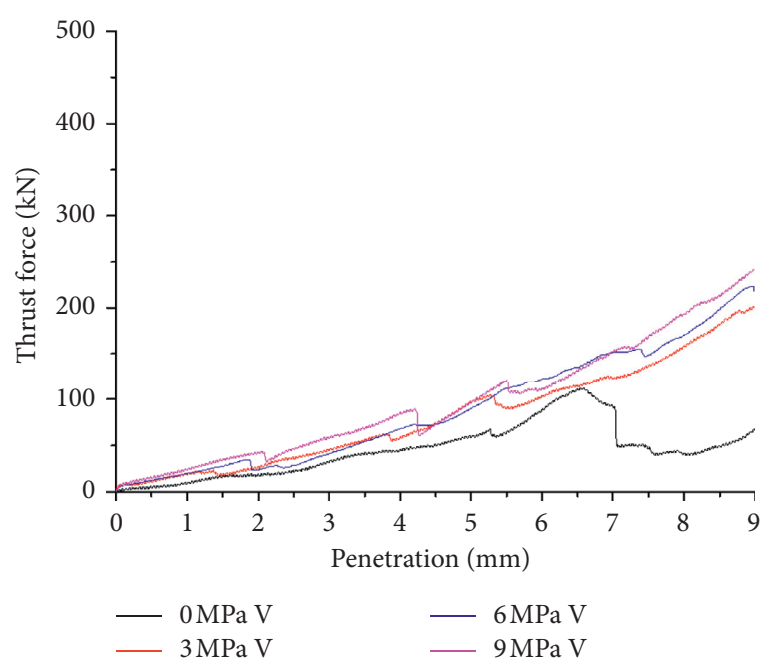

(b)

Figure 10: Thrust cutting force evolution patterns under the $\mathrm{V}$ shape disc cutter. (a) Ultimate penetration $=6 \mathrm{~mm}$; (b) ultimate penetration $=9 \mathrm{~mm}$.

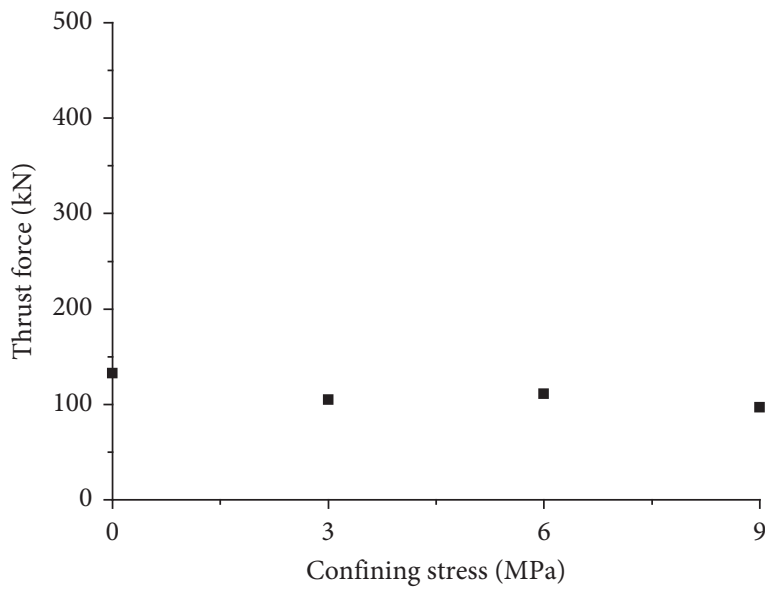

Maximum thrust force for $\mathrm{V}$ shape $6 \mathrm{~mm}$ penetration

(a)

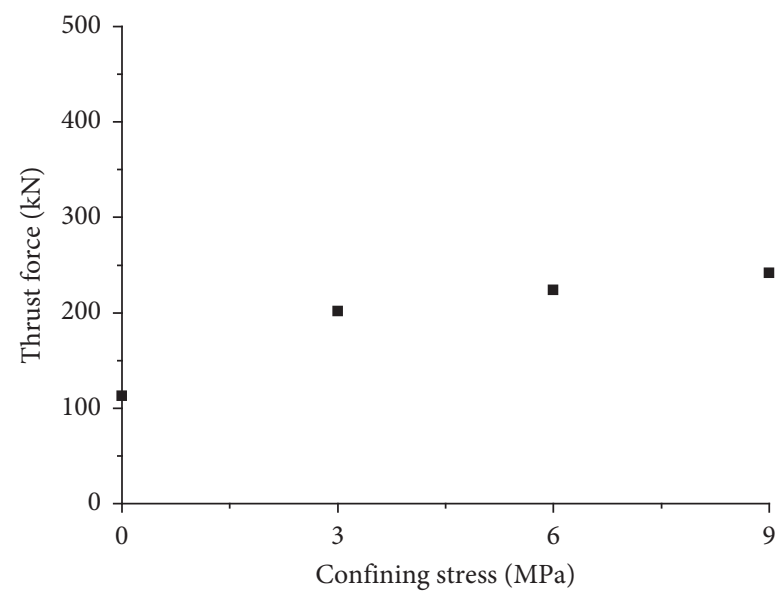

Maximum thrust force for $\mathrm{V}$ shape $9 \mathrm{~mm}$ penetration

(b)

Figure 11: Maximum thrust force for the V shape disc cutter. (a) Ultimate penetration $=6 \mathrm{~mm}$; (b) ultimate penetration $=9 \mathrm{~mm}$.

is clear that when the confining stresses are no higher than $6 \mathrm{MPa}$, penetration energy increases with confining pressure mounting. While if the confinement surpasses a critical value, which is between 6 and $9 \mathrm{MPa}$, then the penetration energy will decrease or flatten with confinement increasing. It is notable that the increasing increments for $9 \mathrm{~mm}$ penetration are much higher than the counterparts for $6 \mathrm{~mm}$ penetration.

The penetration energy evolution for $\mathrm{V}$ shape disc cutter with the ultimate penetration of $6 \mathrm{~mm}$ is shown in Figure $16(\mathrm{a})$. The values are $343,287,305$, and $243 \mathrm{Nm}$ for confining stresses of $0,3,6$, and $9 \mathrm{MPa}$, respectively. No correlation is found between confining stresses and penetration energy. The evolution pattern with the ultimate penetration of $9 \mathrm{~mm}$ is shown in Figure 16(b), in which the penetration energy reaches $405,730,801$, and $872 \mathrm{Nm}$ with confining stresses of $0,3,6$, and $9 \mathrm{MPa}$ respectively; the penetration energy increases monotonically with rising confining stresses. In conclusion, the confining stress's influence on $\mathrm{V}$ shape disc cutter penetration energy is totally different for $6 \mathrm{~mm}$ penetration and $9 \mathrm{~mm}$ penetration, which make it irregular and unpredictable.

\section{Discussion of the Indentation Tests Results}

4.1. Confining Stress's Influence on Thrust Force. The highlighted feature for the CCS disc cutter cutting force evolution is the decreasing and flattening from some point between 


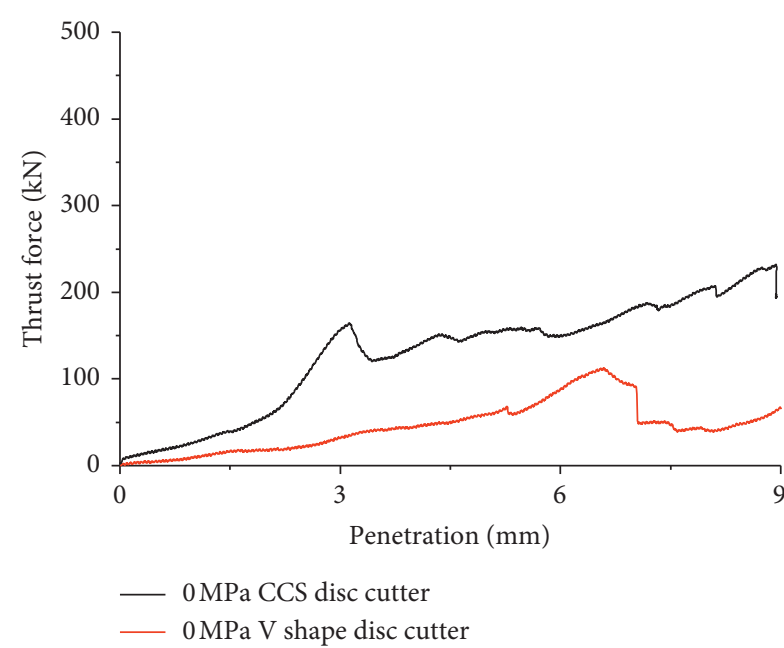

(a)

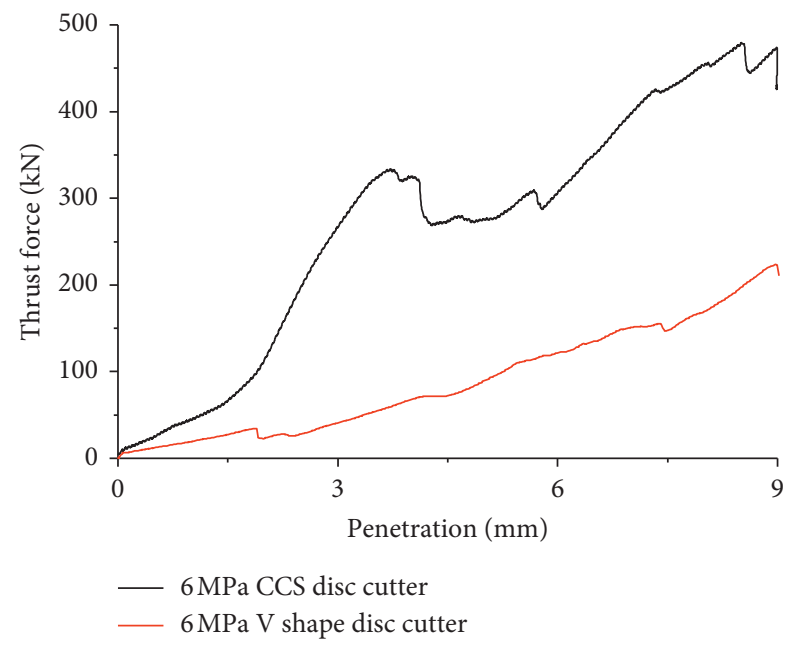

(c)

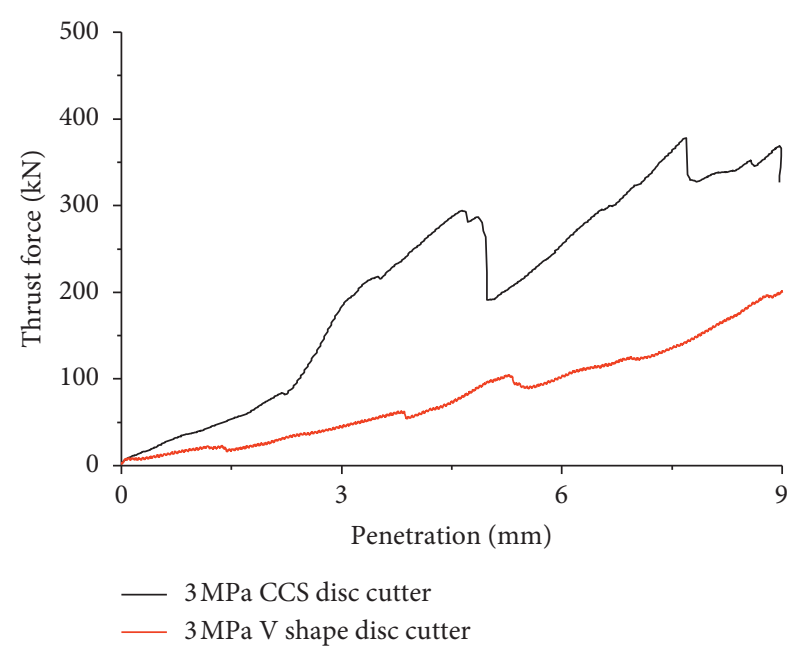

(b)

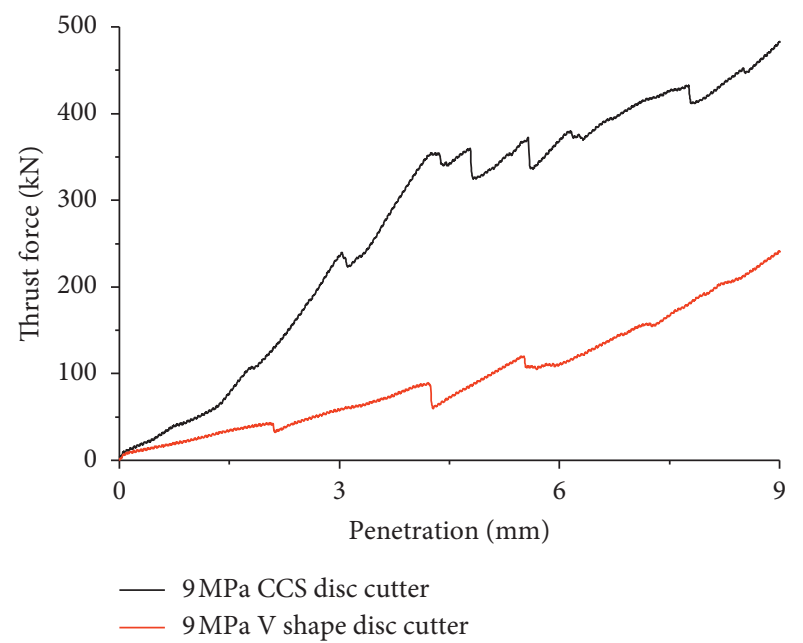

(d)

Figure 12: Comparison of thrust forces between CCS and V shape disc cutters. Confining stress: (a) $0 \mathrm{MPa}$; (b) $3 \mathrm{MPa}$; (c) $6 \mathrm{MPa}$; (d) $9 \mathrm{MPa}$.

$6 \mathrm{MPa}$ and $9 \mathrm{MPa}$ confinement, as shown in Figure 9. It is in line with the findings of the experimental study of Yin et al. [28], as shown in Figure 17 [28]. In contrast, Innaurato et al. [27] found that the maximum load ever increased with the mounting pressures in their experimental study, as shown in Figure 18 [27].

Figure 17 shows that Yin et al. [28] adopted differential confining stresses in different directions, which are the minimum confining stress for one direction and the maximum confining stress for the other. For the tested marble samples, there is a critical confining stress, when the confining stresses are lower than that, the forces for crack initiation increase along with the confinement mounting; while the confining stresses are higher than that, the forces decrease or flatten with confinement mounting. However, the critical confinement phenomenon was not found on the tested granite samples [28]. Yin et al. [28] proposed that the critical confining stress level relates to the compressive strength of rock mass, while no further detailed relationship was given.
Figure 18 shows that the maximum thrust load values increase with confinement mounting up to $10 \mathrm{MPa}$, without any decreasing or flattening, for Botticino and Diorite samples [27]. By comparing the different tests, the tested rocks are of different properties. The tested sandstone's cohesion is $6.8 \mathrm{MPa}$, as shown in Table 1, which is lower than the designed maximum confinement of $9 \mathrm{MPa}$, while the tested rocks' cohesion in Innaurato's study is much higher with values of 16 and $23 \mathrm{MPa}$, as shown in Table 2, which are also higher than the designated maximum confinement of $10 \mathrm{MPa}$. For Yin's tests, Marble's cohesion is $22 \mathrm{MPa}$, and Granite's cohesion is $25 \mathrm{MPa}$, which are lower than and equal to the designed maximum confinement of $25 \mathrm{MPa}$, respectively.

The flattening and decreasing thrust patterns were not found in Innaurato et al.'s tests on Botticino and Diorite and Yin et al.'s tests on Granite because the cohesion values of the tested rocks are no lower than the maximum confining stresses. By relating cohesion values to the maximum thrust forces, it is reasonable to deduce that cohesion value is the turning point for the flattening and decreasing of thrust forces. 


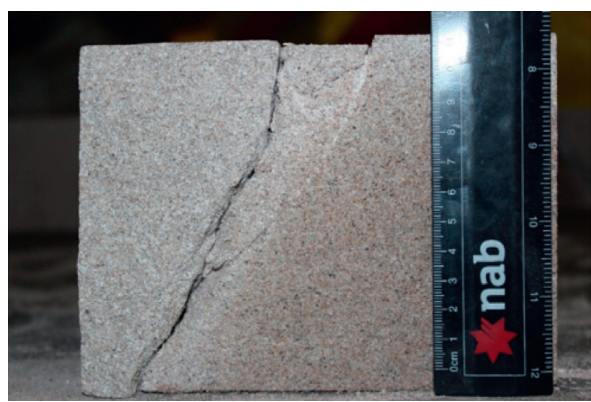

(a)

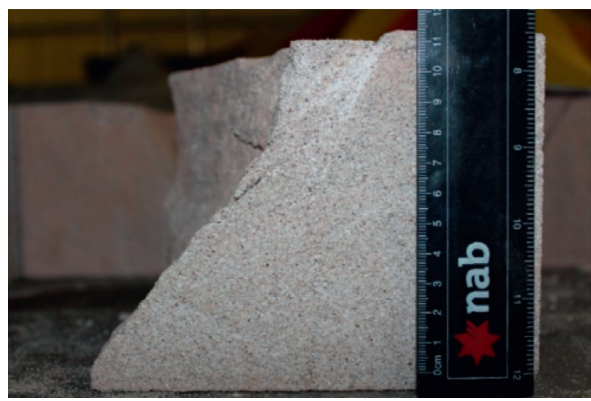

(c)

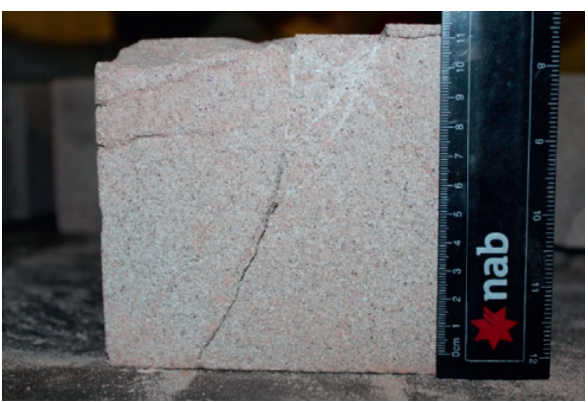

(b)

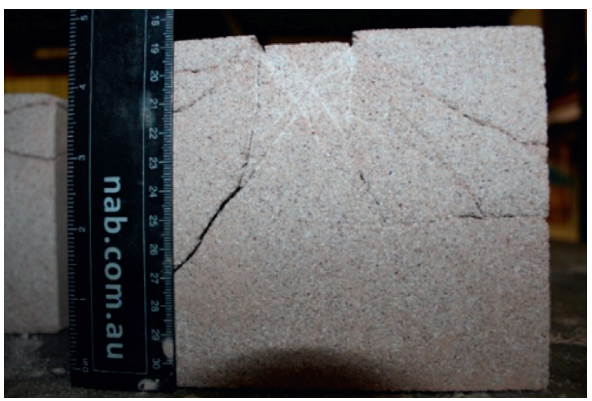

(d)

FIGURE 13: Crack development on the cross section under CCS disc cutter with $6 \mathrm{~mm}$ penetration. Confining stress: (a) $0 \mathrm{MPa}$; (b) $3 \mathrm{MPa}$; (c) $6 \mathrm{MPa}$; (d) $9 \mathrm{MPa}$.

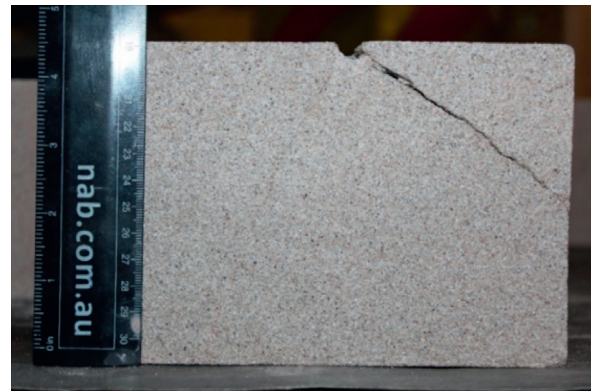

(a)

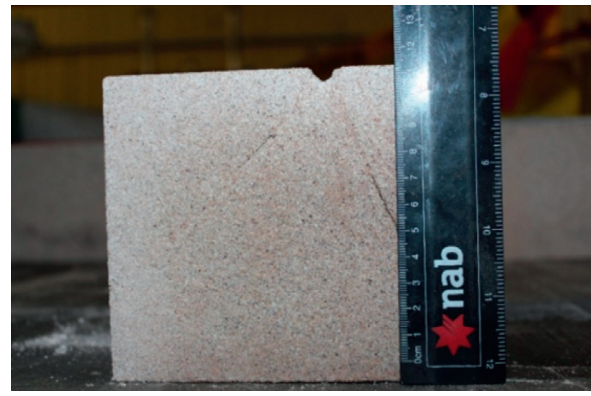

(c)

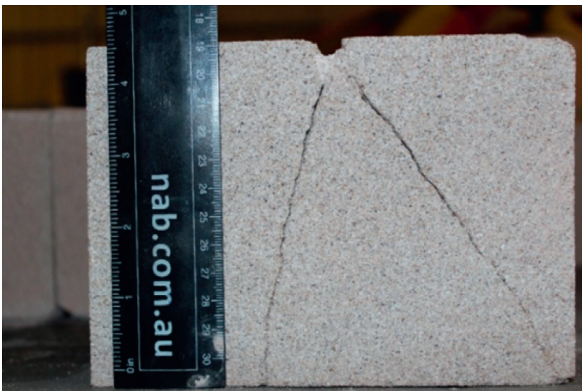

(b)

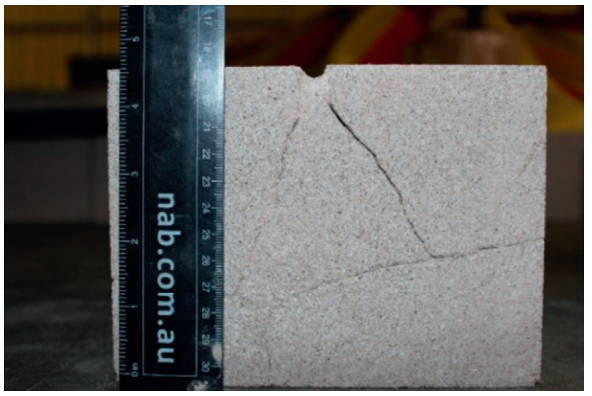

(d)

Figure 14: Crack development on the cross section under V shape disc cutter with $6 \mathrm{~mm}$ penetration.Confining stress: (a) $0 \mathrm{MPa}$; (b) $3 \mathrm{MPa}$; (c) $6 \mathrm{MPa}$; (d) $9 \mathrm{MPa}$.

4.2. Confining Stress's Influence on Boreability. Penetration energy and Field Penetration Index (FPI) are two indicators of boreability. This experimental study shows that, under the CCS disc cutter, decreasing and flattening of penetration energy occurs after the confining stresses surpass a critical value, which is between $6 \mathrm{MPa}$ and $9 \mathrm{MPa}$ for the sandstone. By checking the rock mechanical properties, the critical value is most likely to be of cohesion, which is 


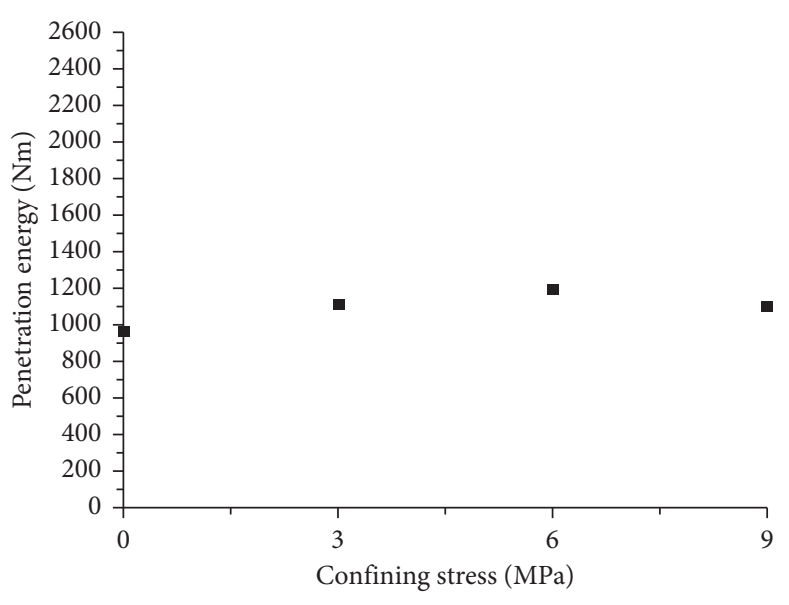

- CCS $6 \mathrm{~mm}$ penetration

(a)

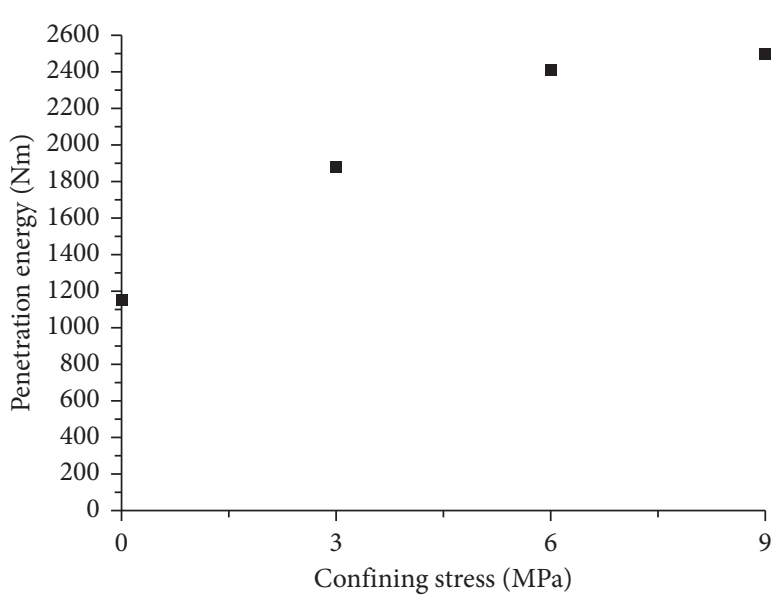

- CCS $9 \mathrm{~mm}$ penetration

Figure 15: Penetration energy varies with confining stresses under the CCS disc cutter. (a) Ultimate penetration $=6 \mathrm{~mm}$; (b) ultimate penetration $=9 \mathrm{~mm}$.

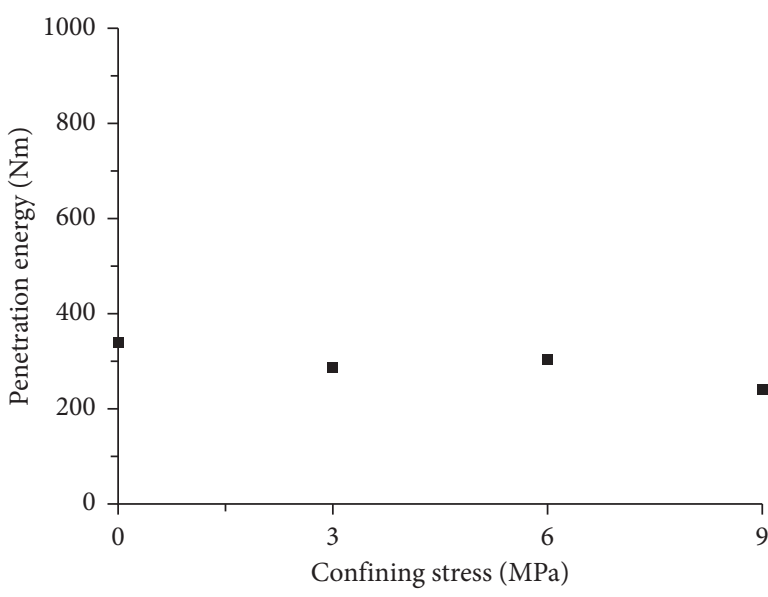

- V shape $6 \mathrm{~mm}$ penetration

(a)

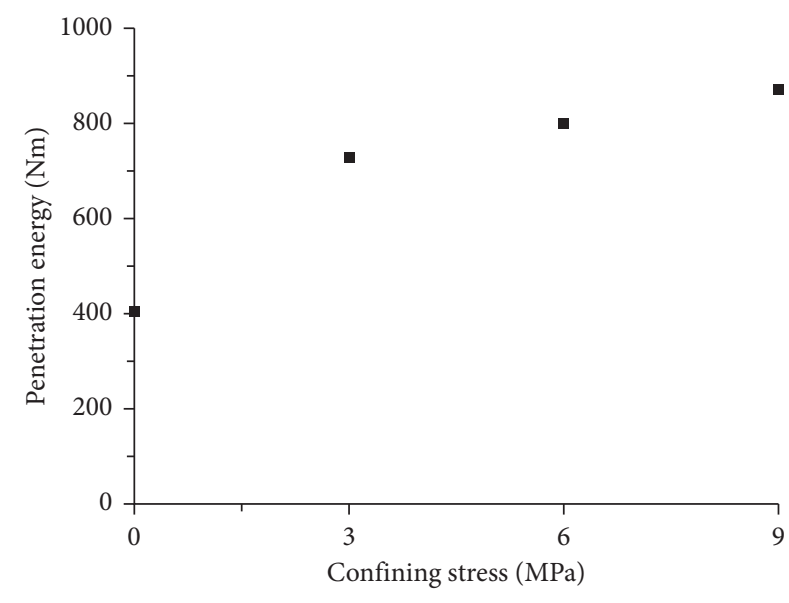

- V shape $9 \mathrm{~mm}$ penetration

(b)

FIgURe 16: Penetration energy varies with confining stresses under V shape disc cutter. (a) Ultimate penetration $=6 \mathrm{~mm}$; (b) ultimate penetration $=9 \mathrm{~mm}$.

6.8 $\mathrm{MPa}$ for the tested rock samples. This means the boreability will increase under CCS disc cutters when the confining stresses surpass the value of cohesion.

The increasing boreability with confinement mounting is also substantiated by the field database collected and compiled by Klein et al. from the perspective of FPI, as shown in Figure 19 [26]. FPI is a normalized parameter, which is defined as the cutter loading divided by the actual penetration rate. It has been used as an important index for boreability. The higher it is, the lower is boreability, and vice versa [32].

Figure 19 shows the correlation between FPI and the ratio of overburden pressure to UCS of rock mass. This finding indicates that, with fixed rock, higher ground pressure, that is, confining stresses, would cause lower FPI and further higher boreability. It supports the penetration energy trend between $6 \mathrm{MPa}$ and $9 \mathrm{MPa}$ confining pressure for the tested sandstone. The 


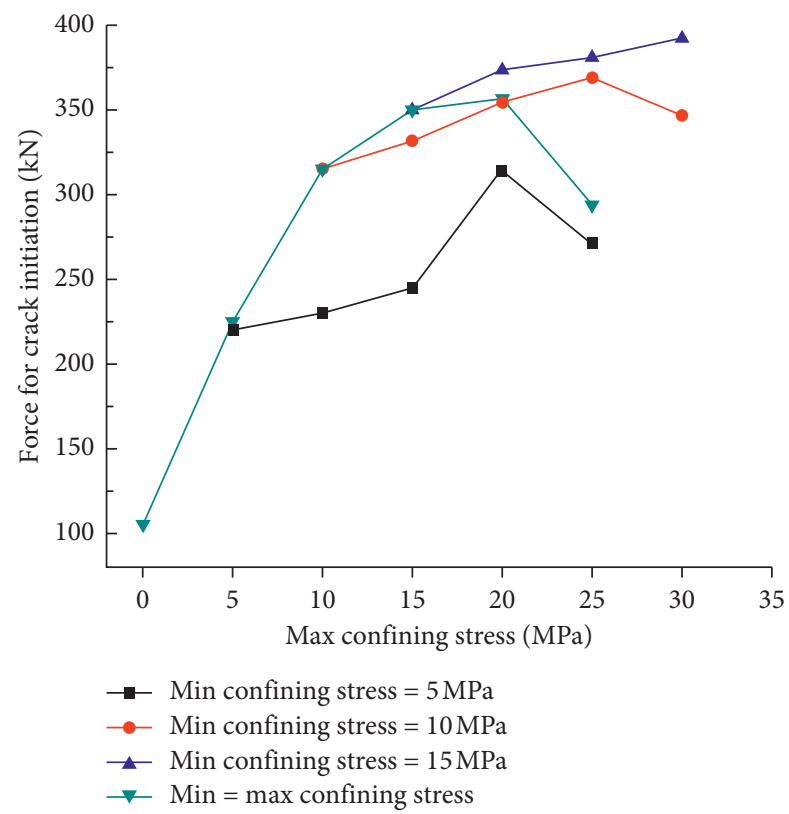

FIgURE 17: Thrust force for crack initiation with the different confining stress levels (marble samples) [28].

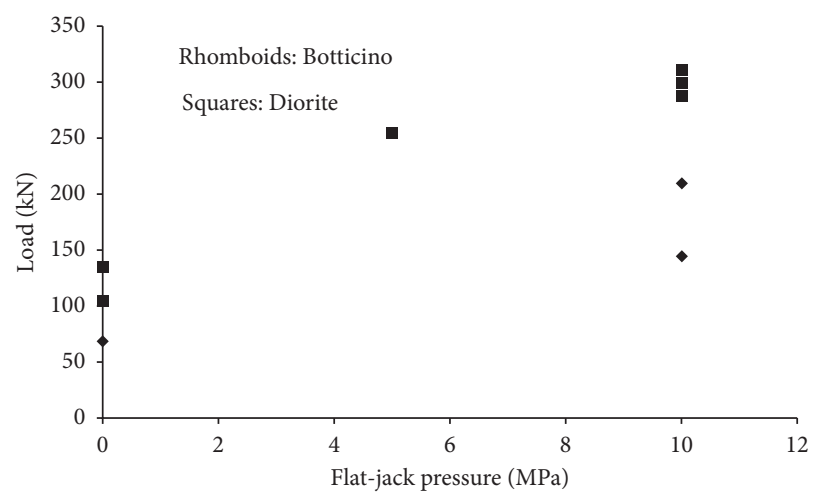

FIGURE 18: Maximum thrust load versus flat-jack confinement pressure for Botticino (rhomboids) and Diorite (squares) under the given settings [27].

TABLE 2: Physical and mechanical properties of the tested rocks adopted in Innaurato et al.'s laboratory tests and Yin et al.'s laboratory tests.

\begin{tabular}{|c|c|c|c|c|}
\hline \multirow{2}{*}{ Properties } & \multicolumn{2}{|c|}{ Innaurato et al.'s tests } & \multicolumn{2}{|c|}{ Yin et al.;s tests } \\
\hline & Botticino & Diorite & Marble & Granite \\
\hline Young's modulus (GPa) & 67 & 30 & 25 & 23 \\
\hline Poisson's ratio & 0.3 & 0.2 & 0.26 & 0.19 \\
\hline Uniaxial compressive strength (MPa) & 142 & 234 & 71 & 108 \\
\hline Cohesion $(\mathrm{MPa})$ & 16 & 23 & 22 & 25 \\
\hline Internal friction angle $\left(^{\circ}\right)$ & 57 & 61 & 40 & 52 \\
\hline Tensile strength $(\mathrm{MPa})$ & 7.2 & 9.3 & 6.6 & 6.5 \\
\hline
\end{tabular}

unfavorable influence of confinement on boreability was not found in Klein's findings, because the collected data mainly had overburden pressure values varying between 0.2 and 0.8 times of the uniaxial compressive strength, while cohesion value is normally 0.1 to 0.2 times the rock UCS value; the sourced projects do not have tunnelling operations falling into this lower range of ground stress regimes. 


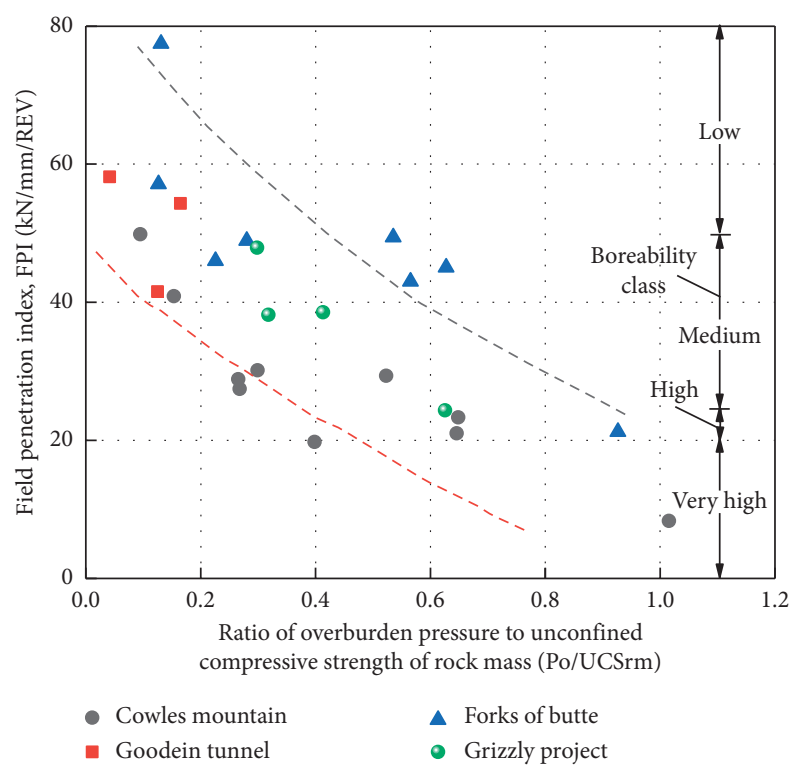

FIGURE 19: FPI correlation with the ratio of overburden pressure divided by UCS of rock mass [26].

\section{Conclusions}

From the perspective of subsurface rock fragmentation, the CCS disc cutter indentation has denser cracks and the crack orientations are more lateral, which is favorable for rock cutting, while the $\mathrm{V}$ shape disc cutter indentation is less sensitive to confining stress mounting, with no notable increase of the crack number and crack reorientation.

The existence of critical confining stress value is found for both maximum thrust force and penetration energy. When the confining stress is lower than the critical value, the maximum thrust force and penetration energy keep increasing with confining stress mounting. As the confining stress level is higher than the critical value, the maximum thrust force and penetration energy will decrease or flatten. By combining with previous studies, and comparing the critical confining stress values to the rock mechanical properties, the critical value is most likely to be of cohesion.

Finding of the critical confining stress value bears notable meaning for establishing cutting force and boreability prediction models which incorporate the confining stress factor, and even the design and optimization of cutter head layout for the TBMs employed in deep underground coal mines. However, more research efforts, including laboratory experiments, field investigation, theoretical analysis, and industrial support, are needed to build such models.

\section{Data Availability}

The data used to support the findings of this study are included within the article.

\section{Conflicts of Interest}

The authors declare that there are no conflicts of interest.

\section{Acknowledgments}

This research was sponsored by the "Fundamental Research Funds for the Central Universities (2020QN44)." Sincere appreciation goes to Alan Grant and Cameron Nelson for their efforts in setting up the experiment.

\section{References}

[1] Q.-S. Liu, H. Xing, K. Shi, and X.-W. Liu, "Utilization of full face roadway boring machine in coal mines deeper than $1000 \mathrm{~m}$ and the key rock mechanics problems," Journal of China Coal Society, vol. 37, no. 12, pp. 2006-2013, 2012.

[2] Q.-S. Liu, K. Shi, and X. Huang, "Feasibility of application of TBM in construction of deep coal mine and its key scientific problems," Journal of Mining and Safety Engineering, vol. 30, no. 5, pp. 633-641, 2013.

[3] D. P. Creedy, "An introduction to geological aspects of methane occurrence and control in British deep coal mines," Quarterly Journal of Engineering Geology and Hydrogeology, vol. 24, no. 2, pp. 209-220, 1991.

[4] L. Wang and Y.-P. Cheng, "Drainage and utilization of Chinese coal mine methane with a coal-methane co-exploitation model: analysis and projections," Resources Policy, vol. 37, no. 3, pp. 315-321, 2012.

[5] M. Bauer, "High performance longwall mining in deep and methane-rich coal deposits in Germany taking into account methods and technologies for controlling the calculated gas liberation," in Proceedings of the International Symposium on Coal Gas Control Technology, Huainan, China, December 2007.

[6] H.-H. Liu, B.-Q Lin, J.-H. Mou, and W. Yang, "Mechanical evolution mechanism of coal and gas outburst," Rock Mechanics and Rock Engineering, vol. 52, no. 5, pp. 1591-1597, 2019.

[7] C. Keles, F. Vasilikou, N. Ripepi, Z. Agioutantis, and M. Karmis, "Sensitivity analysis of reservoir conditions and gas production mechanism in deep coal seams in Buchanan County, Virginia," Simulation Modelling Practice and Theory, vol. 94, pp. 31-42, 2019.

[8] Y.-W. Liu, Q. Wang, W.-X. Chen, M.-J. Liu, and H. Mitri, "Enhanced coalbed gas drainage based on hydraulic flush from floor tunnels in coal mines," International Journal of Mining, Reclamation and Environment, vol. 30, no. 1, pp. 37-47, 2016.

[9] P. Lu, P. Li, J. Chen, C.-J. Zhang, J.-H. Xue, and T. Yu, "Gas drainage from different mine areas: optimal placement of drainage systems for deep coal seams with high gas emissions," International Journal of Coal Science \& Technology, vol. 2, no. 1, pp. 84-90, 2015.

[10] H.-X. Zhou, Q.-L. Yang, Y.-P. Cheng, C.-G. Ge, and J.-X. Chen, "Methane drainage and utilization in coal mines with strong coal and gas outburst dangers: a case study in Luling mine, China," Journal of Natural Gas Science and Engineering, vol. 20, pp. 357-365, 2014.

[11] H.-F. Wang, Y.-P. Cheng, and L. Wang, "Regional gas drainage techniques in Chinese coal mines," Journal of China University of Mining \& Technology, vol. 22, no. 6, pp. 873-878, 2012.

[12] Q.-S. Liu, X. Huang, Q.-M. Gong, L.-J. Du, Y.-C. Pan, and J.-P. Liu, "Application and development of hard rock TBM and its prospect in China," Tunnelling and Underground Space Technology, vol. 57, pp. 33-46, 2016. 
[13] X. Huang, Q.-S. Liu, K. Shi, Y.-C. Pan, and J.-P. Liu, “Application and prospect of hard rock TBM for deep roadway construction in coal mines," Tunnelling and Underground Space Technology, vol. 73, pp. 105-126, 2018.

[14] B. Tang, H. Cheng, Y.-Z. Tang et al., "Experiences of gripper TBM application in shaft coal mine: a case study in Zhangji coal mine, China," Tunnelling and Underground Space Technology, vol. 81, no. 1, pp. 660-668, 2018.

[15] N. Innaurato and P. Oreste, "Theoretical study on the TBM tool-rock interaction," Geotechnical and Geological Engineering, vol. 29, no. 3, pp. 297-305, 2011.

[16] J. Rostami, "Study of pressure distribution within the crushed zone in the contact area between rock and disc cutters," International Journal of Rock Mechanics and Mining Sciences, vol. 57, pp. 172-186, 2013.

[17] I. Evans, "Relative efficiency of picks and discs for cutting rock," in Proceedings of the 3rd Congress on Advances in Rock Mechanics, pp. 1399-1405, Denver, CO, USA, September 1974.

[18] Z.-H. Zhang, The Research on Theory and Techniques of Service Life Management of TBM Disc Cutters, North China Electric Power University, Beijing, China, 2008.

[19] F. F. Roxborough and H. R. Phillips, "Rock excavation by disc cutter," International Journal of Rock Mechanics and Mining Sciences \& Geomechanics Abstracts, vol. 12, no. 12, pp. 361-366, 1975.

[20] L. Ozdemir, R. Miller, and F.-D. Wang, Mechanical Tunnel Boring Prediction and Machine Design, pp. 205-250, Research Applied to National Needs (RANN), National Science Foundation, Washington, DC, USA, 1977.

[21] J. Roby, T. Sandell, J. Kocab, and L. Lindbergh, "Current state of disc cutter design and development directions," Mining Engineering, vol. 61, no. 3, pp. 26-34, 2009.

[22] J. Rostami and L. Ozdemir, "A new model for performance prediction of hard rock TBMs," in Proceedings of the Rapid Excavation and Tunneling Conference, pp. 793-809, Society for Mining, Metallurgy, and Exploration, Inc. (SME), Boston, MA, USA, July 1993.

[23] J. Li, Y.-F. Nie, K. Fu, C. Ma, J.-B. Guo, and M.-X. Xu, "Experiment and analysis of the rock breaking characteristics of disc cutter ring with small edge angle in high abrasive grounds," Journal of the Brazilian Society of Mechanical Sciences and Engineering, vol. 40, 2018.

[24] D. Tumac and C. Balci, "Investigations into the cutting characteristics of CCS type disc cutters and the comparison between experimental, theoretical and empirical force estimations," Tunnelling and Underground Space Technology, vol. 45, no. 1, pp. 84-98, 2015.

[25] P. J. Tarkoy and M. Marconi, "Difficult rock comminution and associated geological conditions," International Journal of Rock Mechanics and Mining Sciences and Geomechanics Abstracts, vol. 29, no. 4, pp. 195-207, 1992.

[26] S. Klein, M. Schmoll, and T. Avery, "TBM performance at four hard rock tunnels in California," in Proceedings of the Rapid Excavation and Tunneling Conference, pp. 61-75, Society for Mining, Metallurgy and Exploration, INC, San Francisco, CA, USA, June 1995.

[27] N. Innaurato, C. Oggeri, P. P. Oreste, and R. Vinai, "Experimental and numerical studies on rock breaking with TBM tools under high stress confinement," Rock Mechanics and Rock Engineering, vol. 40, no. 5, pp. 429-451, 2007.

[28] L.-J. Yin, Q.-M. Gong, H.-S. Ma, J. Zhao, and X.-B. Zhao, "Use of indentation tests to study the influence of confining stress on rock fragmentation by a TBM cutter," International
Journal of Rock Mechanics and Mining Sciences, vol. 72, pp. 261-276, 2014.

[29] Y.-L. Chen and C.-P. Song, "Rock fragmentation characteristics by TBM cutting and efficiency under Bi-lateral confinement," Applied Sciences, vol. 8, no. 4, pp. 498-511, 2018.

[30] R. Ulusay, The ISRM Suggested Methods for Rock Characterization, Testing and Monitoring: 2007-2014, Springer International Publishing, New York, NY, USA, 2015.

[31] R. Gertsch, L. Gertsch, and J. Rostami, "Disc cutting tests in Colorado Red Granite: implications for TBM performance prediction," International Journal of Rock Mechanics and Mining Sciences, vol. 44, no. 2, pp. 238-246, 2007.

[32] P. Nelson, "Factors affecting TBM penetration rates in sedimentary rocks," in Proceedings of the 24th US Symposium on Rock Mechanics (USRMS), American Rock Mechanics Association, College Station, TX, USA, June 1983. 